\title{
Impact of Prenatal Hypoxia on the Development and Behavior of the Rat Offspring
}

\section{Michaela PIEŠOVÁ ${ }^{1,2}$, Romana KOPRDOVÁ ${ }^{1}$, Eduard UJHÁZY ${ }^{1}$, Lucia KRŠKOVÁ ${ }^{3}$, Lucia OLEXOVÁ ${ }^{3}$, Martina MOROVÁ ${ }^{3}$, Tomáš SENKO ${ }^{3}$, Mojmír MACH ${ }^{1}$}

${ }^{1}$ Institute of Experimental Pharmacology and Toxicology, Centre of Experimental Medicine, Slovak Academy of Sciences, Bratislava, Slovak Republic, ${ }^{2}$ Department of Pharmacology, Jessenius Faculty of Medicine in Martin, Comenius University, Martin, Slovak Republic, ${ }^{3}$ Department of Animal Physiology and Ethology, Faculty of Natural Sciences, Comenius University in Bratislava, Bratislava, Slovak Republic

Received October 8, 2020

Accepted November 7, 2020

\section{Summary}

The healthy development of the fetus depends on the exact course of pregnancy and delivery. Therefore, prenatal hypoxia remains between the greatest threats to the developing fetus. Our study aimed to assess the impact of prenatal hypoxia on postnatal development and behavior of the rats, whose mothers were exposed to hypoxia $\left(10.5 \% \mathrm{O}_{2}\right)$ during a critical period of brain development on GD20 for $12 \mathrm{~h}$. This prenatal insult resulted in a delay of sensorimotor development of hypoxic pups compared to the control group. Hypoxic pups also had lowered postnatal weight which in males persisted up to adulthood. In adulthood, hypoxic males showed anxiety-like behavior in the OF, higher sucrose preference, and lower levels of grimace scale (reflecting the degree of negative emotions) in the immobilization chamber compared to the control group. Moreover, hypoxic animals showed hyperactivity in EPM and LD tests, and hypoxic females had reduced sociability compared to the control group. In conclusion, our results indicate a possible relationship between prenatal hypoxia and changes in sociability, activity, and impaired emotion regulation in ADHD, ASD, or anxiety disorders. The fact that changes in observed parameters are manifested mostly in males confirms that male sex is more sensitive to prenatal insults.

\section{Key words \\ Gestational hypoxia - Offspring - Neurodevelopmental disturbances • Behavior rat \\ Corresponding author \\ M. Mach, Institute of Experimental Pharmacology and Toxicology,}

Centre of Experimental Medicine, Slovak Academy of Sciences, Bratislava, Slovak Republic. E-mail: mojmir.mach@savba.sk

\section{Introduction}

An unmutilated course of pregnancy and delivery is necessary for the healthy development of the fetus. The restricted supply of oxygen (hypoxia) during pregnancy, therefore, remains between the greatest threats to the fetus during development (Vlassaks et al. 2013, Piešová and Mach 2020). Incidence of perinatal hypoxia in Europe varies between 0.01-2.8 \% live fullterm births (Giannopoulou et al. 2018). It may cause long-term health problems and increased risk for chronic diseases via fetal programming (Barker 1990). Hypoxia causes an increase in reactive oxygen species production, which can trigger long-term changes in gene-expression patterns (Patterson and Zhang 2010, Ding et al. 2017). These epigenetic changes may affect enzymes involved in the production of stress hormones, potentially predisposing the fetus to chronic cardiovascular and metabolic diseases. Prenatal hypoxia is also associated with lower cardiac performance, which may lead to cardiomyopathies (Patterson and Zhang 2010). Several authors confirmed the importance of oxygen balance during gestation for the proper development of the animal cardiovascular system and its reactivity later in life (Rook et al. 2014, Svitok et al. 2016, Brain et al. 2019).

Although the fetal cells and organs have developed several compensatory responses to hypoxia, 
they are not sufficient enough to protect the developing brain against severe or chronic hypoxia (Nalivaeva et al. 2003, Riljak et al. 2016). If the hypoxia strikes during sensitive stages of the brain maturation, it may cause neuronal apoptosis or permanent changes in neurotransmitter release (McGuire 2007). As prenatal hypoxia can have a deleterious impact on the development of the central nervous system, it may lead to behavioral disturbances later in life. In various studies, changes in sensorimotor development, activity, motor functions, memory, and emotionality were reported in the offspring of hypoxic mothers (Delcour et al. 2012, Zhang et al. 2013, Sedláčková et al. 2014).

Prenatal and perinatal hypoxic conditions also increase the risk of autism spectrum disorder (ASD) and attention deficit hyperactivity disorder (ADHD) (van Handel et al. 2007, Getahun et al. 2013, FroehlichSantino et al. 2014, Giannopoulou et al. 2018). The social skills deficits are a major area of impairment for children and adolescents with these psychiatric disorders (Carpenter Rich et al. 2009, Roberts et al. 2019). In rats, asphyxia in the prenatal period resulted in behavioral changes (especially hyperactivity) resembling some signs of ADHD in children (Dubovický et al. 2007). According to Miguel et al. (2015), neonatal hypoxia-ischemia is an environmental factor that could contribute to the development of behavioral characteristics observed in ADHD that are associated with general brain atrophy. ADHD is characterized not only with inattention, hyperactivity, and impulsivity but also with negative emotionality. Indeed, the development of these behavioral problems has long been known to be related to impairments in emotion regulation and emotionality (Dodge and Pettit 2003, Martel 2009).

The aim of our study was to assess the impact of prenatal hypoxia on postnatal sensorimotor development and behavioral changes of the rats, whose mothers were exposed to hypoxic conditions during a critical period of brain development and maturation.

\section{Methods}

\section{Animals}

The mating of animals was induced by placing virgin female Wistar rats (weight 200-220 g, age 3-4 months, $n=16$; Dobra Voda, Slovakia) in a cage with males in the 3:1 ratio. The presence of spermatozoa in vaginal smear was considered a day 0 of gestation. 3-4 pregnant females were housed in one cage under standard laboratory conditions (12/12 h light/dark cycle; $23 \pm 1{ }^{\circ} \mathrm{C} ; 50-70 \%$ humidity; food and water ad libitum). All experiments were performed according to the Principles of Laboratory Animal Care and were approved by the Ethical Committee of Centre of Experimental Medicine, SAS, and State Veterinary and Food Administration of Slovak Republic. All experiments were performed during the light phase of the cycle.

\section{Induction of hypoxia}

Pregnant rats $(\mathrm{n}=8)$ underwent hypoxia on a gestational day 20 (GD20) for $12 \mathrm{~h}$. Normobaric hypoxia was induced in a hypoxic chamber by a gas mixture $\left(10.5 \% \mathrm{O}_{2}+89.5 \% \mathrm{~N}_{2}\right.$; Linde Gas, Slovakia). The exhaled $\mathrm{CO}_{2}$ was replaced by the gas mixture every $30 \mathrm{~min}$. After the hypoxic insult, the animals were returned to their home cages. Control pregnant rats $(n=8)$ were placed to the hypoxic chamber on GD20 for $12 \mathrm{~h}$ without inducing hypoxia. The females delivered spontaneously, and the day of delivery was considered as a postnatal day 0 ( $\mathrm{PP} 0)$. The pups were assigned to the groups after weaning (PP21) using the single pup per litter rule to minimize genetic bias.

\section{Acid-base balance}

The venous blood gases were measured from vena coccygea lateralis with heparinized injections using the Epoc $^{\mathcal{O}}$ blood analysis system (LABtechnik, s.r.o., Brno, Czech Republic). The samples were collected after $12 \mathrm{~h}$ of hypoxic insult $(\mathrm{n}=6)$ and analyzed within $5 \mathrm{~min}$. The samples from control group $(n=7)$ were collected on GD20.

\section{Postnatal development}

After delivery, the number of pups per litter was assessed on PP1. On PP5, the number of pups in each litter was culled to 10 . The weight and number of pups were also assessed on PP5, PP10, PP15, and PP20. The pups were weighed individually on PP40 (adolescence) and PP92 (adulthood). The neuromotor development of pups was evaluated by the righting reflex and air-righting tests: to assess righting reflex, the pup was laid on the back, and the time needed to turn to the limbs was measured on PP5. The air-righting was studied on PP16 when a pup was dropped in a dorsal position from $30 \mathrm{~cm}$ height on the soft surface. Its ability to land on all four paws was assessed. The sensory development of pups was studied through their startle reflex: on PP12 a glass flask was hit by a metal bar and the freezing reaction of 
a pup was examined. For the statistical analysis of postnatal development, mean results per litter were used.

\section{Behavioral tests in adulthood}

Elevated plus maze (EPM)

The dark plastic apparatus had two opened $(50 \times 10 \mathrm{~cm})$ and two enclosed $(50 \times 30 \times 10 \mathrm{~cm})$ arms placed $50 \mathrm{~cm}$ above the floor level. Animals $(\mathrm{n}=39)$ were placed in the central zone facing the open arm on PP60. Their movements were tracked for $5 \mathrm{~min}$ and analyzed by the ANYMAZETM software. The experimental box was cleaned by $70 \%$ ethanol after each trial.

\section{Light/dark test (LD)}

The apparatus consisted of a white plastic arena $(40 \times 60 \times x 40 \mathrm{~cm})$ with a smaller black box $(40 \times 20 \times 40 \mathrm{~cm}$, opening $8 \times 10 \mathrm{~cm})$ inserted in the arena. Animals $(n=39)$ were placed in the light part of the box facing the opening on PP83. Their movements in the apparatus were recorded for $5 \mathrm{~min}$ and analyzed by the ANYMAZE ${ }^{\mathrm{TM}}$ software. The experimental box was cleaned by $70 \%$ ethanol after each trial.

\section{Open field test (OF)}

The OF box is a dark plastic square-shaped experimental box $(60 \times 60 \times 40 \mathrm{~cm})$. Animals $(n=39)$ were placed in the central part of the box on PP86. Their movements were tracked for $5 \mathrm{~min}$ and analyzed by the ANYMAZETM software. The experimental box was cleaned by $70 \%$ ethanol after each trial.

\section{Sucrose preference test (SPT)}

On the first day of testing, animals $(n=40)$ were introduced to a $1 \%$ sucrose solution for $24 \mathrm{~h}$. For the next $12 \mathrm{~h}$, animals were deprived of food and water. The preference test was carried on from 10:00 to $12: 00$ on PP93. A bottle with the $1 \%$ sucrose solution and a bottle with tap water was placed in the home cages of the rats. Animals could drink ad libitum from both bottles. The sucrose preference was calculated as a division of sucrose consumption by the total consumption of liquids corrected on the weight of each animal.

\section{Social interaction test (SIT)}

The social interaction test was adapted from File (1980). On PP104-105, the offspring were tested for their social interaction behavior with an unknown test partner of the same weight ( \pm max. $10 \mathrm{~g}$ ), sex, and treatment. Pairs of animals were placed in diagonally opposite corners of the box. Their behavior was recorded for 5 min using a digital camera (Logitech, Lausanne, SUI). Pairs were tested in random order in the dark plastic square-shaped box $(60 \times 60 \times 40 \mathrm{~cm})$ between $14: 30$ and 17:00. The latency until the first contact, total duration, and the frequency of socio-cohesive (following, chasing, mutual sniffing, genital investigation, climbing over, crawling under, allogrooming, time in close proximity) and socio-aversive (escape, mounting, tail biting) interactions were measured.

\section{Rat grimace scale (RGS)}

RGS method was adapted from Sotocinal et al. (2011) and described in detail in Senko et al. (2017). On PP112-113, each animal was first observed in the home cage and subsequently transferred to the immobilization chamber (adapted to the size of the animal), which is considered a mildly stressful context characterized by immobilization and social isolation (Paré and Glavin 1986, Brown et al. 2005). Animals were tested for $10 \mathrm{~min}$ in both conditions. The facial expressions of rats were recorded using a camera (Lumix DMC-TZ 7, Panasonic, Japan) (1 picture/min, in total 10 pictures of each animal in the home cage and immobilization chamber, respectively). Each picture was analyzed by three independent trained observers, who examined action units expressing the emotional state of the animal.

The action units were scored from 0 to 2 , with the score denoting the intensity of emotional expression: " $0 "=$ high confidence that the action unit was absent; "1"=high confidence of a moderate appearance of the action unit or equivocation over its presence or absence; "2"=high confidence of an obvious appearance of the action unit (Sotocinal et al. 2011). Subsequently, the RGS score for each animal was calculated from the mean score of the individual ratings of action units. Reliability was quantified by comparing average action unit scores across coders, using the intraclass correlation coefficient (ICC) (Shrout and Fleiss 1979). The overall ICC was 0.81 (ICC3), 0.93 (ICC3k). Therefore, the scores of the three observers were averaged and used for statistical analysis. An index of emotional reactivity was calculated as the difference between the RGS score in the stress situation and the RGS score in the home cage.

\section{Statistics}

All data were analyzed using Shapiro-Wilk's W-test to determine whether they fit a normal distribution. One-way ANOVA, followed by Fisher's LSD post hoc test, was used to evaluate the effect of hypoxia on the acid- 
base balance of the rat dams. Postnatal development, number of pups, and their weight were analyzed using the $t$-test or Mann-Whitney $U$-test. If all the parameters in the behavioral test had a normal distribution, they were analyzed by a two-way ANOVA (factors: treatment, gender) followed by a post hoc Fisher test (EPM, sucrose preference, RGS). If one or more parameters were significant in the normality test, then the $t$-test and/or Mann-Whitney $U$-test were used separately for each gender (LD, OF, SIT). Data were analyzed using the program STATISTICA 7.0 (StatSoft, Tulsa, OK, USA). The $\mathrm{p}<0.05$ was recognized as statistically significant. Results are presented as mean \pm S.E.M.

\section{Results}

\section{Acid-base balance}

Venous blood gas analysis showed a state of compensated respiratory alkalosis in hypoxic dams (Table 1). The hypoxic environment led to hyperventilation that exceeded metabolic demands and resulted in a decline of the arterial partial pressure of carbon dioxide $\left(\mathrm{pCO}_{2}\right)$ and a rise in the $\mathrm{pH}$ of the blood. Lowered $\mathrm{pCO}_{2}$ led to a compensatory decrease in bicarbonate $\left(\mathrm{HCO}_{3}{ }^{-}\right)$, which is associated with chronic respiratory alkalosis.

\section{Postnatal development}

Hypoxia did not affect the number of pups per litter. However, the weight of hypoxic pups showed a trend to decrease, especially on PP10 (U=19.5, $\mathrm{Z}=1.855, \mathrm{p}=0.06$ ). This decrease of weight was significant in males in adolescence $(t=3.279, D F=35$, $\mathrm{p}<0.01)$ and in adulthood $(\mathrm{t}=2.293, \mathrm{DF}=35, \mathrm{p}<0.05)$. However, the weight of juvenile and adult hypoxic females did not differ from control levels (Table 2).

Table 1. Acid-base balance of the rat dams. (*p<0.05; ** $p<0.01 ; * * * p<0.001-$ statistically significant compared to control).

\begin{tabular}{lcccccc}
\hline & Control (n=7) & Hypoxia $(\mathbf{n}=\mathbf{6})$ & Units & Fdf (1.11) value & $\mathbf{p ~ v a l u e ~}$ & Abbreviations \\
\hline$p H$ & $7.49 \pm 0.01$ & $7.56 \pm 0.01^{* *}$ & $\mathrm{pH}$ units & 18.9 & $\mathbf{p}<\mathbf{0 . 0 1}$ & \\
$p \mathrm{CO}_{2}$ & $35.43 \pm 1.93$ & $17.6 \pm 1.83^{* * *}$ & $\mathrm{~mm} \mathrm{Hg}$ & 44.15 & $\mathbf{p}<\mathbf{0 . 0 0 1}$ & Carbon dioxide, partial pressure \\
$\mathrm{pO}_{2}$ & $48.41 \pm 4.41$ & $43.68 \pm 0.86$ & $\mathrm{~mm} \mathrm{Hg}$ & 0.95 & $\mathrm{p}=0.35$ & Oxygen, partial pressure \\
$\mathrm{cHCO}_{3}{ }^{-}$ & $26.64 \pm 1.09$ & $15.58 \pm 1.30^{* * *}$ & $\mathrm{mmol} / 1$ & 42.97 & $\mathbf{p}<\mathbf{0 . 0 0 1}$ & Actual bicarbonate concentration \\
\hline
\end{tabular}

Table 2. Postnatal development of the rat pups. (*p<0.05; ** $p<0.01-$ statistically significant compared to control).

\begin{tabular}{|c|c|c|c|c|}
\hline & & & Control & Нypoxia \\
\hline \multirow{5}{*}{\multicolumn{2}{|c|}{ Pups per litter }} & PP1 & $10.11 \pm 0.65$ & $10.88 \pm 0.58$ \\
\hline & & PP5 & 10.0 & 10.0 \\
\hline & & PP10 & $9.86 \pm 0.14$ & $9.88 \pm 0.13$ \\
\hline & & PP15 & $9.71 \pm 0.18$ & $9.5 \pm 0.19$ \\
\hline & & PP20 & $9.71 \pm 0.19$ & $9.5 \pm 0.20$ \\
\hline \multirow{4}{*}{ Postnatal weight ( $g$ ) } & & PP5 & $11.57 \pm 0.42$ & $10.55 \pm 0.46$ \\
\hline & & PP10 & $19.65 \pm 0.6$ & $17.52 \pm 1.08$ \\
\hline & & PP15 & $29.27 \pm 3.2$ & $27.51 \pm 1.24$ \\
\hline & & PP20 & $40.64 \pm 4.26$ & $38.13 \pm 1.58$ \\
\hline \multirow{4}{*}{ Weight $(g)$} & \multirow{2}{*}{ Male } & PP40 & $135.21 \pm 3.44$ & $120.78 \pm 2.69 * *$ \\
\hline & & PP92 & $340.05 \pm 5.75$ & $323.17 \pm 4.51^{*}$ \\
\hline & \multirow{2}{*}{ Female } & PP40 & $116.7 \pm 1.99$ & $113.75 \pm 1.45$ \\
\hline & & PP92 & $217.65 \pm 3.68$ & $219.35 \pm 3.22$ \\
\hline \multicolumn{3}{|l|}{ Righting reflex - time (s) } & $1.73 \pm 0.07$ & $2.61 \pm 0.25^{* *}$ \\
\hline \multicolumn{3}{|l|}{ Air-righting - accomplished (\%) } & $84.99 \pm 5.76$ & $67.92 \pm 6.4$ \\
\hline \multicolumn{3}{|l|}{ Startle reflex-accomplished (\%) } & $73.35 \pm 6.84$ & $53.61 \pm 6.09 *$ \\
\hline
\end{tabular}


The postnatal motor development of hypoxic pups was slowed compared to the control group: Pups from the hypoxic group needed significantly longer time in the righting reflex test $(\mathrm{U}=4.0, \mathrm{Z}=-2.946, \mathrm{p}<0.01)$, and the percentage of hypoxic pups to accomplish air-righting trended to decrease compared to control group $(\mathrm{t}=1.942$, $\mathrm{DF}=14, \mathrm{p}=0.07)$. The percentage of hypoxic pups who accomplished startle reflex was also significantly decreased in the hypoxic group compared to the control group $(\mathrm{t}=2.156, \mathrm{DF}=14, \mathrm{p}<0.05)$, which suggests their slower sensory development.

A

Elevated plus maze

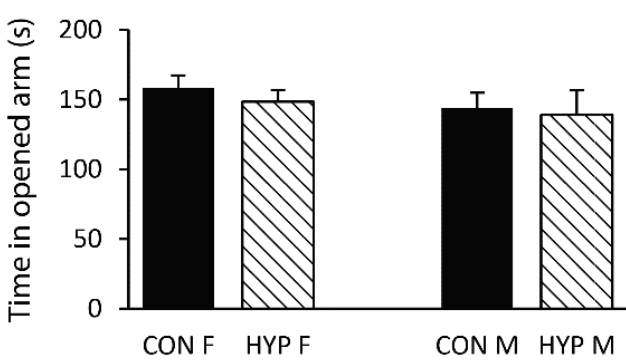

C

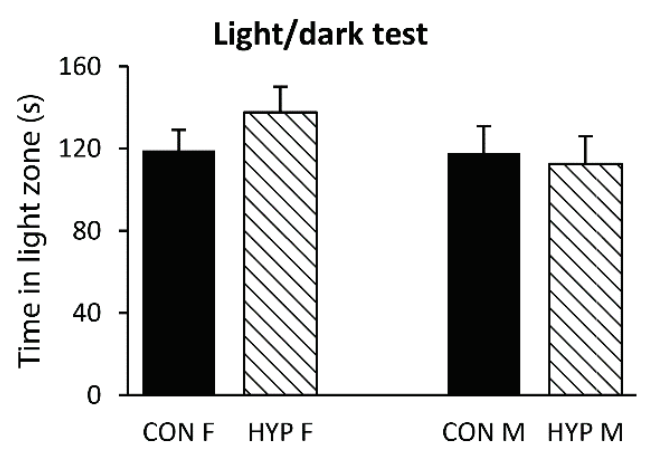

\section{Behavior in adulthood}

In the elevated plus-maze, animals did not show anxiety-like behavior, as there was no effect of treatment or gender on the time spent in the open arm (Fig. 1A). However, hypoxic treatment had a significant effect on the distance travelled in this maze $(\mathrm{F}(1,35)=4.967, \mathrm{p}<0.05)$, and post hoc test showed an increase in the distance travelled in this test in hypoxic females $(\mathrm{p}<0.05)$, but not males, compared to control group (Fig. 1B), indicating hyperactivity of hypoxic females.

B

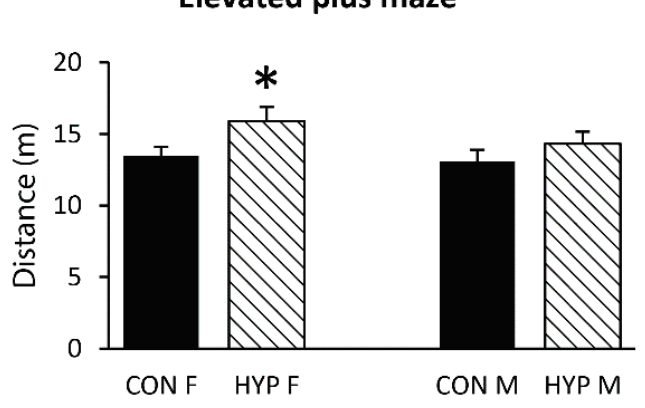

D

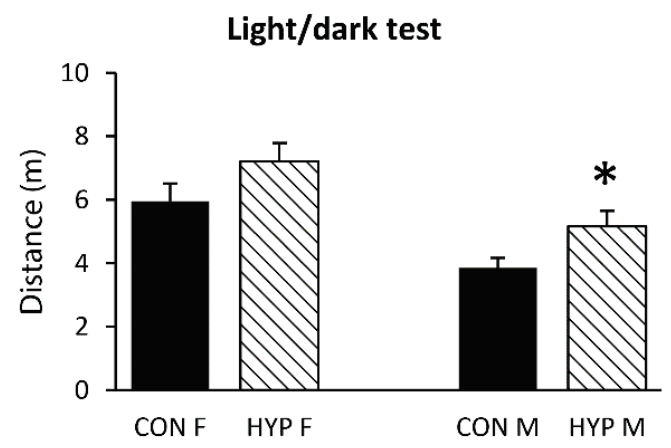

Fig. 1. Effect of prenatal hypoxia on the time rats spent in the open arm (A) and distance (B) they travelled in EPM; and time spent in the light zone (C) and activity (D) in LD test. $* p<0.05$ - statistically significant compared to control group (CON=control, $\mathrm{HYP}=$ hypoxia, $\mathrm{F}=$ female, $\mathrm{M}=$ male).

In the light/dark test, males from the hypoxic group travelled significantly longer distance than the control group $(\mathrm{t}=-2.266, \mathrm{DF}=16, \mathrm{p}<0.05$, Fig. 1D), which suggests their hyperactivity. The time they spent in the light zone (which indicates the extent of anxiety-like behavior of rats) was, however, not changed compared to the control group (Fig. 1C). The behavior of hypoxic females did not differ from the control group in this test.

Open field test showed an increase in anxietylike behavior of hypoxic males: They spent shorter time $(\mathrm{t}=2.248, \mathrm{DF}=16, \mathrm{p}<0.05$, Fig. $2 \mathrm{~A})$ and travelled shorter distance $(t=2.726, D F=16, p<0.05$, Fig. $2 B)$ in the central zone of the OF compared to control males. The time females spent in the central zone and the distance they travelled in it were not changed. The activity of hypoxic rats was not changed in this test, as there was no significant difference between hypoxic and control groups in the distance they travelled in this test.

Sucrose preference is used to assess anhedonia and depression-like behavior of animals. An effect of gender $\quad\left(\mathrm{F}_{(1,36)}=48.529, \quad \mathrm{p}<0.001\right) \quad$ and treatment $\left.\left(F_{(1,36)}=6.113\right), p<0.05\right)$ on the sucrose preference of rat offspring was seen. The post hoc test revealed a significantly elevated preference of sucrose only in male 
A

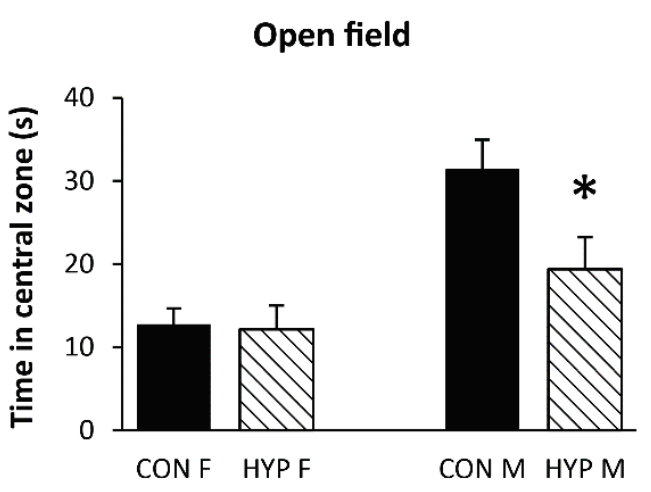

C Sucrose preference test

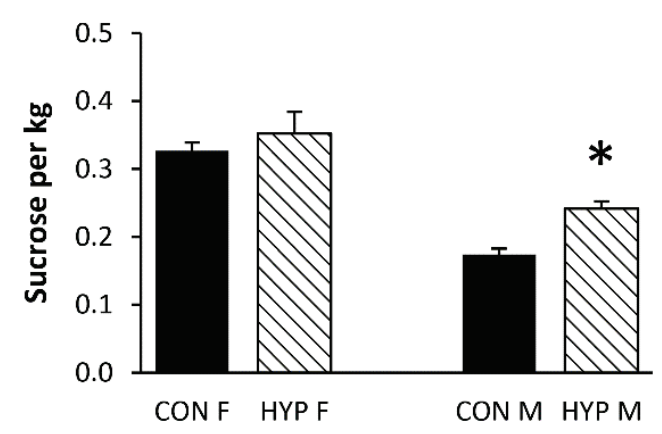

B

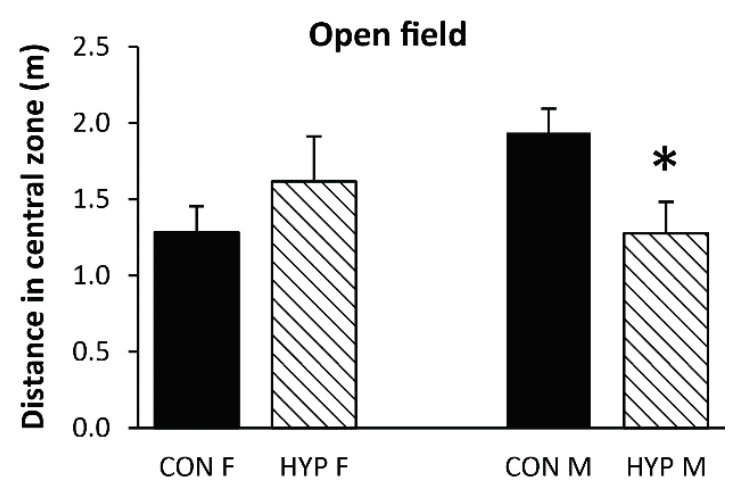

D Social interaction test

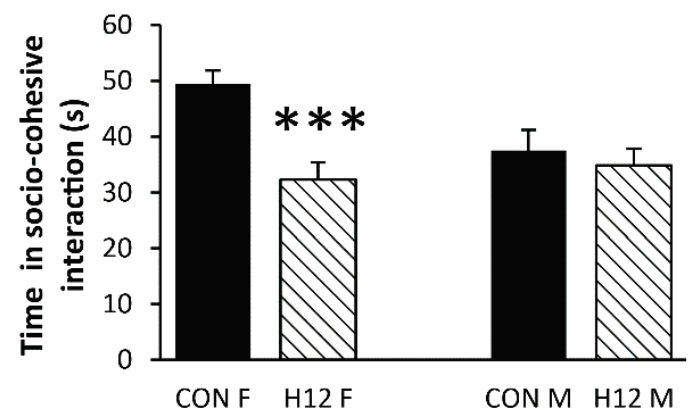

Fig. 2. Effect of prenatal hypoxia on the time (A) and distance (B) the offspring travelled in OF test, its preference of sucrose (C) and socio-cohesive interactions (D). $* p<0.05 ; * * * p<0.001$ - statistically significant compared to control group (CON=control, $\mathrm{HYP}=$ hypoxia, $\mathrm{F}=$ female, $\mathrm{M}=$ male).

hypoxic rats $(\mathrm{p}<0.05)$ (Fig. 2C).

In the social interaction test, hypoxic females (but not males) spent less time in socio-cohesive interaction in comparison with control females $(\mathrm{t}=4.33$, $\mathrm{DF}=38, \mathrm{p}<0.001$ ) (Fig. 2D). However, the latency until the first contact and the total frequency of socio-cohesive interactions were not changed by hypoxia. Socio-aversive interactions were observed only in few animals, and no differences have been found between groups.

An effect of gender $(F(1,33)=30.3, p<0.001)$ was seen on the Rat grimace scale score in the home cage (Fig. 3A), while in the restraint stress, we observed an effect of gender $\left(F\left({ }_{1,33}\right)=65.321, \quad \mathrm{p}<0.001\right)$ and treatment $(\mathrm{F}(1,33)=10.275, \mathrm{p}<0.01)$. Hypoxic males achieved a significantly lower score compared to control males $(p<0.01)$ in restraint stress (Fig. 3B). We also found a significant effect of treatment $\left(\mathrm{F}\left({ }_{1,33}\right)=23.121\right.$, $\mathrm{p}<0.001)$ and gender $(\mathrm{F}(1,33)=2.216, \mathrm{p}<0.001)$ on the emotional reactivity of rats: Animals exposed to hypoxia reached a significantly lower emotional reactivity (males: $\mathrm{p}<0.001$, females: $\mathrm{p}<0.05$ ) compared to control animals (Fig. 3C).

\section{Discussion}

In our study, respiratory alkalosis was found in rat dams as a compensatory response to the hypoxic environment due to the increase in ventilation, which proved the suitability of the hypoxic model used. Prenatal hypoxia caused a significant delay in postnatal development of sensory and motor reflexes of the offspring that are inevitable for the adaptation of pups to the new environment. It also caused a decrease in postnatal weight (especially in male rats) in the hypoxic group which persisted up to adulthood. Our findings are in agreement with other studies that found a negative impact of prenatal hypoxia on postnatal development of the rat pups (Dubrovskaya and Zhuravin 2010, Liu et al. 2011, Watzlawik et al. 2015), especially on their body and brain measures (Tong et al. 2009) and weight (GonzalezRodriguez et al. 2014, Walton et al. 2016). In our study, hypoxia had a negative impact on the postnatal sensorimotor development of the affected pups that was comparable to other studies (Dubovický et al. 2004, Liu et al. 2011, Sanches et al. 2012, Kumar et al. 2017). 
A

Rat grimace scale

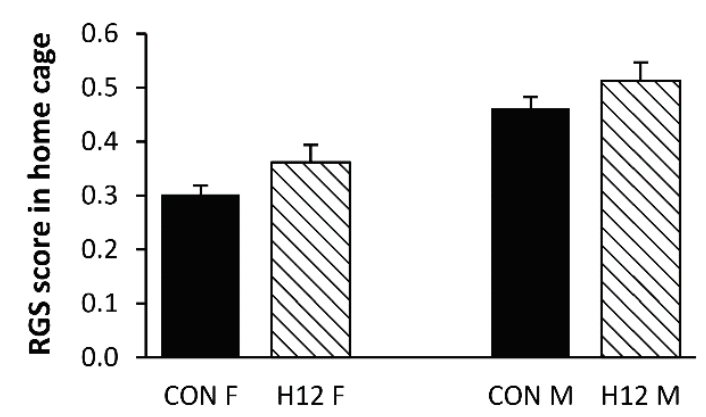

B

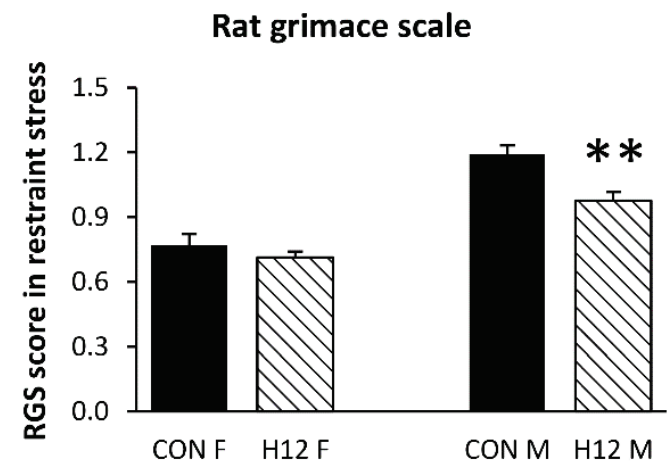

C

\section{Rat grimace scale}

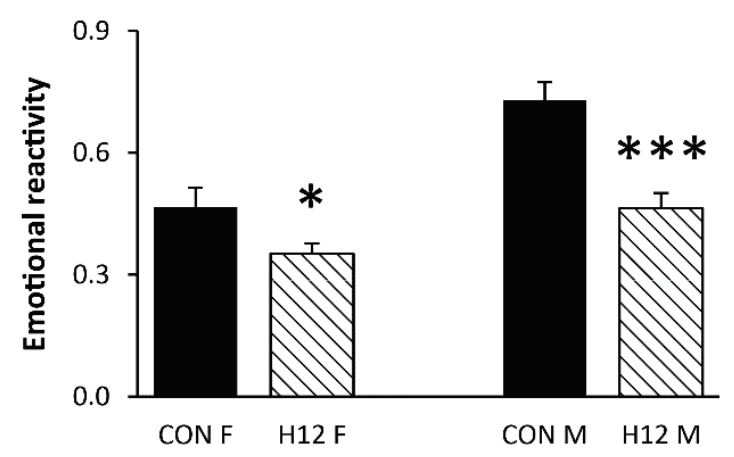

Fig. 3. Effect of prenatal hypoxia on the rat grimace scale score in the home cage (A), in restraint stress (B), and on the emotional reactivity $(\mathbf{C})$ of the offspring. $* \mathrm{p}<0.05, * * \mathrm{p}<0.01, * * * \mathrm{p}<0.001-$ statistically significant compared to control group (CON=control, $\mathrm{HYP}=$ hypoxia, $\mathrm{F}=$ female, $\mathrm{M}=$ male).

Prenatal hypoxia is thought to change the emotionality of rats, which manifests as their anxiety-like behavior in various behavioral tests. In our study, hypoxic males showed anxiety-like behavior in the $\mathrm{OF}$ in adulthood, as they spent a significantly shorter time in the central zone and travelled a shorter distance in it. Prenatal hypoxia and hypoxia-ischemia also led to the anxiety-like behavior of rats in many other studies (Weitzdoerfer et al. 2004, Sab et al. 2013, Howell and Pillai 2014, Sedláčková et al. 2014).

Males from the hypoxic group showed higher sucrose preference compared to control rats in our study. However, in the sucrose preference test, the loss of sucrose preference is traditionally interpreted as a marker of anhedonia and depression-like behavior in animals (Matthews et al. 1995). Although a more recent study found a correlation between higher sucrose consumption and increased immobility in the forced swim test (Brenes et al. 2006); we have found no effect of hypoxia on the immobility of animals in the forced swim test (data not shown). However, we observed a higher intake of food in hypoxic males during the testing (data not shown). We, therefore, assume that the increase in sucrose consumption in hypoxic males may be caused by their hyperphagia.

Hypoxic animals showed hyperactivity in EPM and LD tests, which is in accordance with other studies on hypoxic or hypoxic-ischemic animals (Dubovický et al. 2004, Delcour et al. 2012). Exposure to hypoxia also reduced the sociability of affected individuals. Hypoxic females spent less time in sociocohesive interaction in comparison with control females. These results support the existence of a possible relationship between prenatal hypoxia and changes in sociability and activity in ADHD and ASD (Carpenter Rich et al. 2009, Roberts et al. 2019), but also in anxiety disorders (Roberts et al. 2019).

Although we did not see differences between the control and hypoxic group in the grimace scale (reflecting the degree of lived negative emotions) in the home cage, hypoxic males showed lower levels of RGS in the immobilization chamber compared to the control group. This fact is also confirmed by the Emotional Reactivity Index itself, which was lower in animals from the 
hypoxic group. These findings may be related to impairments in emotion regulation related to either ADHD or ASD (Dodge and Pettit 2003, Martel 2009, Mazefsky and White 2014).

The fact that changes in observed parameters are manifested mostly in males confirms that male sex is more sensitive to prenatal impact, as evidenced by the higher prevalence of ASD or ADHD in men (Nøvik et al. 2006, Willcutt 2012, Werling and Geschwind 2013). We also confirmed results from our previous study (Sedláčková et al. 2014) and other studies (Tashima et al. 2001, Waddell et al. 2016), in which males were more sensitive to hypoxia or hypoxia-ischemia than female animals. The weaker effect of hypoxia and other adverse impacts on females is thought to be caused by the sexual dimorphism in microglial activation, cell death pathways, or circulating gonadal hormones during prenatal development (for an extensive review see CharriautMarlangue, Besson and Baud 2017).

\section{Conclusions}

In conclusion, our study shows a deleterious impact of late maternal hypoxia on the early development of the rat offspring. Moreover, our results indicate a possible relationship between prenatal hypoxia and changes in sociability, activity, and impaired emotion regulation in ADHD, ASD, or anxiety disorders. Our model also showed higher sensitivity of male offspring to prenatal impacts. All in all, our model can be used for assessing the prenatal programming mechanisms and testing of prevention and/or treatment of the prenatal hypoxia complications.

\section{Conflict of Interest}

There is no conflict of interest.

\section{Acknowledgements}

This study was supported by the grant VEGA 2/0154/20, SAS Programme for PhD students' grant APP0054 and H2020 - LOGIC LAB - MSCA-ITN-2018 - Molecular logic lab-on-a-vesicle for intracellular diagnostics. We would like to thank LABtechnik s.r.o. in Brno, Czech Republic for lending us the Epoc ${ }^{\odot}$ blood analysis system device.

\section{References}

BARKER DJ: The fetal and infant origins of adult disease. BMJ 301: 1111 , 1990. https://doi.org/10.1136/bmj.301.6761.1111

BRAIN KL, ALLISON BJ, NIU Y, CROSS CM, ITANI N, KANE AD, HERRERA EA, SKEFFINGTON KL, BOTTING KJ, GIUSSANI DA: Intervention against hypertension in the next generation programmed by developmental hypoxia. PLoS Biol 17: e2006552, 2019. https://doi.org/10.1371/journal.pbio.2006552

BRENES SÁENZ JC, VILLAGRA OR, FORNAGUERA TRÍAS J: Factor analysis of forced swimming test, sucrose preference test and open field test on enriched, social and isolated reared rats. Behav Brain Res 169: 57-65, 2006. https://doi.org/10.1016/j.bbr.2005.12.001

BROWN SM, HENNING S, WELLMAN CL: Mild, short-term stress alters dendritic morphology in rat medial prefrontal cortex. Cereb Cortex N Y N 1991 15: 1714-1722, 2005. https://doi.org/10.1093/cercor/bhi048

CARPENTER RICH E, LOO SK, YANG M, DANG J, SMALLEY SL: Social functioning difficulties in ADHD: association with PDD risk. Clin Child Psychol Psychiatry 14: 329-344, 2009. https://doi.org/10.1177/1359104508100890

CHARRIAUT-MARLANGUE C, BESSON V, BAUD O: Sexually dimorphic outcomes after neonatal stroke and hypoxia-ischemia. Int J Mol Sci 19: 61, 2017. https://doi.org/10.3390/ijms19010061

DELCOUR M, OLIVIER P, CHAMBON C, PANSIOT J, RUSSIER M, LIBERGE M, XIN D, GESTREAU C, ALESCIOLAUTIER B, GRESSENS P, VERNEY C, BARBE MF, BAUD O, COQ J-O: Neuroanatomical, sensorimotor and cognitive deficits in adult rats with white matter injury following prenatal ischemia: Brain dysfunctions after gestational ischemia. Brain Pathol 22: 1-16, 2012. https://doi.org/10.1111/j.1750-3639.2011.00504.X

DING P, REN D, HE S, HE M, ZHANG G, CHEN Y, SANG H, PENG Z, YAN W: Sirt1 mediates improvement in cognitive defects induced by focal cerebral ischemia following hyperbaric oxygen preconditioning in rats. Physiol Res 66: 1029-1039, 2017. https://doi.org/10.33549/physiolres.933544 
DODGE KA, PETTIT GS: A biopsychosocial model of the development of chronic conduct problems in adolescence. Dev Psychol 39: 349-371, 2003. https://doi.org/10.1037/0012-1649.39.2.349

DUBOVICKÝ M, MACH M, BRUCKNEROVÁ I, UJHÁZY E: Effect of perinatal anoxia on exploratory behaviour of rat offspring. Acta Physiol 191: 57, 2007.

DUBOVICKÝ M, UJHÁZY E, KOVACOVSKÝ P, NAVAROVÁ J, JURÁNI M, SOLTÉS L: Effect of melatonin on neurobehavioral dysfunctions induced by intrauterine hypoxia in rats. Cent Eur J Public Health 12 (Suppl): S23-S25, 2004.

DUBROVSKAYA NM, ZHURAVIN IA: Ontogenetic characteristics of behavior in rats subjected to hypoxia on day 14 or day 18 of embryogenesis. Neurosci Behav Physiol 40: 231-238, 2010. https://doi.org/10.1007/s11055009-9235-2

FILE SE: The use of social interaction as a method for detecting anxiolytic activity of chlordiazepoxide-like drugs. J Neurosci Methods 2: 219-238, 1980. https://doi.org/10.1016/0165-0270(80)90012-6

FROEHLICH-SANTINO W, LONDONO A, CLEVELAND S, TORRES A, PHILLIPS J, COHEN B, TORIGOE T, MILLER J, FEDELE A, COLLINS J, SMITH K, LOTSPEICH L, CROEN LA, OZONOFF S, LAJONCHERE C, GRETHER JK, HARA RO, HALLMAYER J: Prenatal and perinatal risk factors in a twin study of autism spectrum disorders. J Psychiatr Res 54: 100-108, 2014. https://doi.org/10.1016/j.jpsychires.2014.03.019

GETAHUN D, FASSETT M, JACOBSEN S: Association between psychosocial disorder during pregnancy and childhood attention deficit hyperactivity disorder by gestational age and race / ethnicity. Am J Obstet Gynecol 208 (Suppl): S296, 2013. https://doi.org/10.1016/j.ajog.2012.10.041

GIANNOPOULOU I, PAGIDA MA, BRIANA DD, PANAYOTACOPOULOU MT: Perinatal hypoxia as a risk factor for psychopathology later in life: the role of dopamine and neurotrophins. Hormones 17: 25-32, 2018. https://doi.org/10.1007/s42000-018-0007-7

GONZALEZ-RODRIGUEZ PJ, XIONG F, LI Y, ZHOU J, ZHANG L: Fetal hypoxia increases vulnerability of hypoxic-ischemic brain injury in neonatal rats: Role of glucocorticoid receptors. Neurobiol Dis 65: 172-179, 2014. https://doi.org/10.1016/j.nbd.2014.01.020

HOWELL KR, PILLAI A: Effects of prenatal hypoxia on schizophrenia-related phenotypes in heterozygous Reeler mice: A genexenvironment interaction study. Eur Neuropsychopharmacol 24: 1324-1336, 2014. https://doi.org/10.1016/j.euroneuro.2014.05.011

KUMAR AJ, TAKADA SH, MOTTA-TEIXEIRA LC, LEE VY, XAVIER GF, NOGUEIRA MI: Sex differences in somatic and sensory motor development after neonatal anoxia in Wistar rats. Behav Brain Res 333: 242-250, 2017. https://doi.org/10.1016/j.bbr.2017.07.009

LIU W, CHEN O, CHEN C, WU B, TANG J, ZHANG JH: Protective effects of hydrogen on fetal brain injury during maternal hypoxia. In: Intracerebral Hemorrhage Research. ZHANG J, COLOHAN A (eds), Springer Vienna, Vienna, 2011, pp 307-311. https://doi.org/10.1007/978-3-7091-0693-8 51

MARTEL MM: Research review: A new perspective on attention-deficit / hyperactivity disorder: emotion dysregulation and trait models. J Child Psychol Psychiatr 50: 1042-1051, 2009. https://doi.org/10.1111/j.14697610.2009.02105.X

MATTHEWS K, FORBES N, REID IC: Sucrose consumption as an hedonic measure following chronic unpredictable mild stress. Physiol Behav 57: 241-248, 1995. https://doi.org/10.1016/0031-9384(94)00286-E

MAZEFSKY CA, WHITE SW: Emotion regulation concepts \& practice in autism spectrum disorder. Child Adolesc Psychiatry Clin NA 23: 15-24, 2014. https://doi.org/10.1016/j.chc.2013.07.002

MCGUIRE W: Perinatal asphyxia. BMJ Clin Evid 2007: 0320, 2007.

MIGUEL PM, SCHUCH CP, ROJAS JJ, CARLETTI JV, DECKMANN I, MARTINATO LHM, PIRES AV, BIZARRO L, PEREIRA LO: Neonatal hypoxia-ischemia induces attention-deficit hyperactivity disorder-like behavior in rats. Behav Neurosci 129: 309-320, 2015. https://doi.org/10.1037/bne0000063

NALIVAEVA NN, FISK L, CANET AVILES RM, PLESNEVA SA, ZHURAVIN IA, TURNER AJ: Effects of prenatal hypoxia on expression of amyloid precursor protein and metallopeptidases in the rat brain. Int J Pept Res Ther 10: 455-462, 2003. https://doi.org/10.1007/s10989-004-2402-y 
NØVIK ST, HERVAS A, RALSTON SJ, DALSGAARD S, PEREIRA RR, LORENZO MJ: Influence of gender on Attention-Deficit / Hyperactivity Disorder in Europe - ADORE. Eur Child Adolesc Psychiatry 15: 15-24, 2006. https://doi.org/10.1007/s00787-006-1003-z

PARÉ WP, GLAVIN GB: Restraint stress in biomedical research: A review. Neurosci Biobehav Rev 10: 339-370, 1986. https://doi.org/10.1016/0149-7634(86)90017-5

PATTERSON AJ, ZHANG L: Hypoxia and fetal heart development. Curr Mol Med 10: 653-666, 2010. https://doi.org/10.2174/156652410792630643

PIEŠOVÁ M, MACH M: Impact of perinatal hypoxia on the developing brain. Physiol Res 69: 199-213, 2020. https://doi.org/10.33549/physiolres.934198

RILJAK V, KRAF J, DARYANANI A, JIRUŠKA P, OTÁHAL J: Pathophysiology of perinatal hypoxic-ischemic encephalopathy - biomarkers, animal models and treatment perspectives. Physiol Res 65 (Suppl 5): S533-S545, 2016. https://doi.org/10.33549/physiolres.933541

ROBERTS JE, CRAWFORD H, WILL EA, HOGAN AL, MCQUILLIN S, TONNSEN BL, CONNOR SO, ROBERTS DA, BREWE AM: Infant social avoidance predicts autism but not anxiety in fragile $\mathrm{X}$ syndrome. Front Psychiatry 10: 1-10, 2019. https://doi.org/10.3389/fpsyt.2019.00199

ROOK W, JOHNSON CD, CONEY AM, MARSHALL JM: Prenatal hypoxia leads to increased muscle sympathetic nerve activity, sympathetic hyperinnervation, premature blunting of neuropeptide y signaling, and hypertension in adult life novelty and significance. Hypertension 64: 1321-1327, 2014. https://doi.org/10.1161/HYPERTENSIONAHA.114.04374

SAB IM, FERRAZ MMD, AMARAL TAS, RESENDE AC, FERRAZ MR, MATSUURA C, BRUNINI TMC, MENDES-RIBEIRO AC: Prenatal hypoxia, habituation memory and oxidative stress. Pharmacol Biochem Behav 107: 24-28, 2013. https://doi.org/10.1016/j.pbb.2013.04.004

SANCHES EF, ARTENI NS, SPINDLER C, MOYSÉS F, SIQUEIRA IR, PERRY ML, NETTO CA: Effects of preand postnatal protein malnutrition in hypoxic-ischemic rats. Brain Res 1438: 85-92, 2012. https://doi.org/10.1016/j.brainres.2011.12.024

SEDLÁČKOVÁ N, KRAJČIOVÁ M, KOPRDOVÁ R, UJHÁZY E, BRUCKNEROVÁ I, MACH M: Subchronic perinatal asphyxia increased anxiety-and depression-like behaviors in the rat offspring. Neuro Endocrinol Lett 35 (Suppl 2): 214-220, 2014.

SENKO T, OLEXOVÁ L, MOKOŠÁKOVÁ M, KRŠKOVÁ L: Angiotensin II enhancement during pregnancy influences the emotionality of rat offspring (Rattus norvegicus) in adulthood. Potential use of the rat grimace scale. Neuro Endocrinol Lett 38: 117-123, 2017.

SHROUT PE, FLEISS JL: Intraclass correlations: uses in assessing rater reliability. Psychol Bull 86: 420-428, 1979. https://doi.org/10.1037/0033-2909.86.2.420

SOTOCINAL SG, SORGE RE, ZALOUM A, TUTTLE AH, MARTIN LJ, WIESKOPF JS, MAPPLEBECK JC, WEI P, ZHAN S, ZHANG S, MCDOUGALL JJ, KING OD, MOGIL JS: The rat grimace scale: a partially automated method for quantifying pain in the laboratory rat via facial expressions. Mol Pain 7: 55, 2011. https://doi.org/10.1186/1744-8069-7-55

SVITOK P, MOLCAN L, STEBELOVA K, VESELA A, SEDLACKOVA N, UJHAZY E, MACH M, ZEMAN M: Prenatal hypoxia in rats increased blood pressure and sympathetic drive of the adult offspring. Hypertens Res 39: 501-505, 2016. https://doi.org/10.1038/hr.2016.21

TASHIMA L, NAKATA M, ANNO K, SUGINO N, KATO H: Prenatal influence of ischemia-hypoxia-induced intrauterine growth retardation on brain development and behavioral activity in rats. Biol Neonate 80: 81-87, 2001. https://doi.org/10.1159/000047125

TONG W, CHEN W, OSTROWSKI RP, MA Q, SOUVENIR R, ZHANG L, ZHANG JH, TANG J: Maternal hypoxia increases the activity of MMPs and decreases the expression of TIMPs in the brain of neonatal rats. Dev Neurobiol 70: 182-194, 2009. https://doi.org/10.1002/dneu.20770

VAN HANDEL M, SWAAB H, DE VRIES LS, JONGMANS MJ: Long-term cognitive and behavioral consequences of neonatal encephalopathy following perinatal asphyxia: a review. Eur J Pediatr 166: 645-654, 2007. https://doi.org/10.1007/s00431-007-0437-8 
VLASSAKS E, GAVILANES AWD, VLES JSH, DEVILLE S, KRAMER BW, STRACKX E, MARTINEZMARTINEZ P: The effects of fetal and perinatal asphyxia on neuronal cytokine levels and ceramide metabolism in adulthood. J Neuroimmunol 255: 97-101, 2013. https://doi.org/10.1016/j.jneuroim.2012.09.011

WADDELL J, HANSCOM M, SHALON EDWARDS N, MCKENNA MC, MCCARTHY MM: Sex differences in cell genesis, hippocampal volume and behavioral outcomes in a rat model of neonatal HI. Exp Neurol 275: 285-295, 2016. https://doi.org/10.1016/j.expneurol.2015.09.003

WALTON SL, SINGH RR, TAN T, PARAVICINI TM, MORITZ KM: Late gestational hypoxia and a postnatal high salt diet programs endothelial dysfunction and arterial stiffness in adult mouse offspring: Prenatal hypoxia and vascular function in mice. J Physiol 594: 1451-1463, 2016. https://doi.org/10.1113/JP271067

WATZLAWIK JO, KAHOUD RJ, O'TOOLE RJ, WHITE KAM, OGDEN AR, PAINTER MM, WOOTLA B, PAPKE LM, DENIC A, WEIMER JM, CAREY WA, RODRIGUEZ M: Abbreviated exposure to hypoxia is sufficient to induce CNS dysmyelination, modulate spinal motor neuron composition, and impair motor development in neonatal mice. PLoS One 10: e0128007, 2015. https://doi.org/10.1371/journal.pone.0128007

WEITZDOERFER R, GERSTL N, POLLAK D, HOEGER H, DREHER W, LUBEC G: Long-term influence of perinatal asphyxia on the social behavior in aging rats. Gerontology 50: 200-205, 2004. https://doi.org/10.1159/000078348

WERLING DM, GESCHWIND DH: Sex differences in autism spectrum disorders. Curr Opin Neurol 26: 146-153, 2013. https://doi.org/10.1097/WCO.0b013e32835ee548

WILLCUTT EG: The prevalence of DSM-IV attention-deficit / hyperactivity disorder: a meta-analytic review. Neurotherapeutics 9: 490-499, 2012. https://doi.org/10.1007/s13311-012-0135-8

ZHANG X, LI L, ZHANG X, XIE W, LI L, YANG D, HENG X, DU Y, DOODY RS, LE W: Prenatal hypoxia may aggravate the cognitive impairment and Alzheimer's disease neuropathology in APPSwe/PS1A246E transgenic mice. Neurobiol Aging 34: 663-678, 2013. https://doi.org/10.1016/j.neurobiolaging.2012.06.012 